\title{
Procedural Model for Maintenance Service Penetration into the Mature Market: The Case of Lithuania
}

\author{
Rolandas DREJERIS, Eglè DREJJERIENÉ
}

\begin{abstract}
Neither scientific nor special literature contains systematic information about the actions required for maintenance service market penetration, and most of this kind of research is purely theoretical, not linked to practical possibilities and addressing these issues only fragmentary. Procedural model with flexible structure is developed; the model consists of 9 reasoned components. The article provides systematized information about the market penetration, based on modern scientific findings. The proposed model shows all the necessary actions, sequence of the performances, content of the actions and possibilities for using. The maintenance services market penetration model was tested and found to be suitable. This resulted in the emergence of a new maintenance company in the Lithuanian market. The use of the model will help to design a market penetration strategy for maintenance companies. Also, the use of the model can help to penetrate the maintenance market of any country which has a market economy and legitimized competition.
\end{abstract}

Keywords: customers' satisfaction; maintenance service; mature market; model; penetration strategy

\section{INTRODUCTION}

Many young professional entrepreneurs in technical and technological sciences complete their studies in higher education institutions every year and look for possibilities to start their own business. It can be agreed, as Yitshaki and Kropp [1] argued, that passion rather than money is primary motivation for some of them. Recently, there is a rather high competition in the maintenance service market. So, how an enterprising person can penetrate the today's maintenance market which is quite complete? This question is relevant for every business pioneer in this area and sometimes for innovative business professionals in any competitive market.

So, how to begin such activity? How to choose a strategy, which is the most suitable for the specific maintenance actions? What processes need to be taken? These questions are not answered in detail yet in any kind of literature, and such circumstances are regarded as the problem of the paper. Solution to this problem would help many maintenance companies to behave boldlier in competition and achieve better results. Scientific and special literature contains much information about new product penetration strategies, but most of the research is purely theoretical and not related to practical possibilities. The aim of the article is to propose a procedural model of the market penetration actions, customized for the providers of maintenance services, which would allow service businesses to find answers to the previously listed questions.

In order to create a procedural model, scientific information on market penetration issues is analyzed with a purpose to find solutions of successful penetration. The keywords were used, such as penetration, market, mature market, complete market and customers' satisfaction. The information is systematized by product themes and service penetration actions. The lack of this kind of research, in particular addressing the maintenance field, led to the investigation of possibilities of using product penetration actions in the service sector. It means that results have to be structured according to the possibilities of the actions to be used in service business and, even more precisely, synthesized to determine the sequence of the actions after they are assessed from the point of logic view, feasibility, business integrity and possibilities to adapt to the maintenance sector. Moreover, in order to ascertain that the model presented in the paper is suitable, a questionnaire survey of consumers was carried out with determined components of the model, and information found on different websites was analyzed to provide basis for the conclusions made hereinafter. The statistical date was analyzed as well in order to make qualitative decisions. The process of developing the theoretical model was followed by taking practical actions. This research methodology has been a marked success as the created model was suitable for real business conditions.

The article analyzed maintenance services for catering companies. These services usually include installation of equipment and software, technical maintenance during their operation, also, repairing of equipment. There may be additional services in this type of activity: consultations how to operate new equipment, personnel training, maintenance of electricity and water supply networks, and other technical issues related to the use of equipment. Thus, the maintenance covers a whole range of activities related to the proper operation of catering equipment.

\section{ANALYSIS OF THE REQUIREMENTS FOR THE MODEL OF PENETRATING INTO THE MAINTENANCE SERVICE MATURE MARKET}

Penetration strategy is theoretically differentiated by certain aspects in the classic marketing literature: by the nature of the markets, by the speed of penetration and by the product's innovativeness degree. Referring to strategy issues, Freeman [2] cites Ansoff who claims that penetration of goods/services into mature markets has to be deeper, through more aggressive marketing techniques. According to the same Freeman [2], the aforementioned techniques should lead to increase purchase frequency and assist in attracting customers of competing companies.

Furthermore, it is also possible to search for product sales opportunities in new markets, or to choose a consumers segment that has not yet decided about a service provider. Many sources considered to be classic literature make a distinction between slow market penetration (at a 
high price and low support expenses) and rapid penetration (low price and high support expenses), and offer different methods for the implementation of global innovations and little modified new products [3]. This means that the model should be flexible, e.g. application of the model enables assessment of a variety of business situations.

Meyer and YenThi Thu Tran [4] emphasized that penetration techniques depend on the country's culture and traditions. It means that it is important to investigate both aspects specific consumers culture and some cultural traits of service providers. Results of this study should be also reflected in the model of penetration into the mature maintenance market. In general, the situation in goods/services market is similar to that in sports. In order to win, you always need to achieve the best results [5]. This means the need to beat market leaders or to achieve the results that are similar to those of the market leaders in terms of service quality.

So, as mentioned above, the first steps in looking for a niche in the existing market should be clearly directed towards identification of market participants. These procedures are necessary to assess possibilities for better meeting the needs of existing customers. Results of this study will allow determining the market leader and adjust the performance of further studies, because orientation to the market leader defines the service quality according to certain aspects. In addition, it will be possible not only to understand the market leadership position, but also to measure company's possibilities to achieve better quality of services. In order to identify ways to provide services better than the leader, it is necessary to identify some quality parameters of the leading service by conducting a consumers' survey. So, the next step would be to specify the quality indicators of the service from the point of view of consumers' satisfaction, trying to discern the existing gaps in satisfying customer needs by competitors, to identify possibilities for improving the quality of services and to predict the direction in which changes in customers' needs will develop in order to meet the customers' needs better than competitors in the near future. In this study, it is also appropriate to distinguish the market segment in which current market participants, at least, meet the needs of the customers. The following information would help to identify the direction leading to more opportunities for meeting the needs of this market segment and thus to devise market penetration strategies. Kotler and Armstrong [6] further specify the proposed actions at this stage, arguing that it is appropriate to focus on the market leader and strive to provide a service better than the market leader's, this way beginning to take even the smallest market share and then gradually increasing the provision of services that are more diversified and a better quality. This approach is particularly relevant for the business which is concerned with stabilized, long-term relationships between the service provider and the customer.

Implementation of new services and offering better quality of existing services was also identified as an opportunity for mature market penetration by Runge et al. [7] and Tax, Brown [8]. They also pointed out the need for market segmentation. It is obvious that development of new services contributes to company's competitiveness and better customer satisfaction, potentially creating preconditions for market penetration. By the way, not only completely new installation services can facilitate a new entrant to penetrate the mature market, but also services provided as a slight modification of some service settings to highlight a certain segment of customers whose needs are met by better modified services or those with changed parameters. Results of customers satisfaction studies should show whether it is appropriate to choose a completely different segment of customers (i.e., expand the network of customers, provide services to those customers who do not use the leaders' services) or to attract, with the use of promotional instruments, at least a part of customers from other service business organizations, i.e. not market leader's customers.

Kotler and Armstrong [6], as well Bohli, Sorge and Wesgoff [9] offer selling products at low prices as a classical instrument to penetrate a market. The possibility of obtaining services at a lower price is particularly relevant for the customers of maintenance services, as this kind of services is usually procured under long-term contracts. Accordingly, lower prices would lead to savings. This is particularly important for new companies, which do not have enough funds yet. Thus, the proposal to reduce service prices and to stimulate the purchase of services (i.e. to sell at least some of the services cheaper than the market leader) merits attention and it is appropriate for a new entrant to analyze the possibilities to stimulate this way customer interest into the proposed product. Relatively low pricing of new services can accelerate the process of market penetration $[10,11]$.

The level of customers' needs satisfaction is usually determined on the basis of customer surveys. Processed using mathematical-statistical methods, the results of a questionnaire survey provide a more objective picture of the customer needs and lead to more sound conclusions [12]. It is appropriate applying to specialized market research companies, which carry out such studies for service providers that do not have a chance to do customer surveys themselves.

Liu and McClure [13] divide consumers' culture into individualistic, collectivist, western and eastern. In the individualistic culture, customers are more likely to voice their complaints than those in the collectivist culture; moreover, customers in the collectivist culture are more likely to express private responses than those in the individualistic culture. According to them, another reasonable research direction is an online analysis of complaints and comments about the quality of maintenance. Not all users prefer to express their opinion about a service quality both verbally or in writing; for some clients it may be better to express their opinions about service providers or anger for a possible failure or improper action in a more secure environment. Often these service users 'empty' themselves writing complaints in their home environment where they feel braver (safer), though such complaints may be completely biased. In addition, users not only complain in a virtual environment, but also like to discuss other aspects of services, consult, ask for advice, give offers or even express their dreams, i.e. share not only negative experiences. There is a large number of national websites available for that purpose. So, the analysis of the Internet space can also help to grasp the thread, which can lead improving the quality of services and be worthwhile choosing for a market newcomer. It is reasonable to 
classify all customer complaints and recommendations regarding service quality improvements into groups, systematize and sometimes even synthesize them for using the results of such analysis for further decisions.

Another classical tool for sales promotion, which can be often found in scientific literature, is sponsorship activities that are appropriate to apply by a new entrant as a market penetration possibility. Advertising of a new product as one of the support tools is mentioned by Sood, James, and Tellis [14] and many other researchers. According to Kotler and Armstrong [6], also Oke [15], this and other support measures (personal selling, public relations) could also enhance the level of sales. Likewise, those authors state that it is expedient to use more intensified and comparability measures for advertising a new product and to look for opportunities to do it better than other competitors; only such use of advertising would make it easier to penetrate into a mature market.

According to Sood, James, and Tellis [14], advertising is also identified as one of the main and the most effective support measures in the service sector. After exploring the opportunities to provide services cheaper and having determined the purposefulness of the implementation of new services, the sponsorship methods and justification of their need must be clearly defined.

So, one of the most appropriate measures for a new service to penetrate into the market is attractive advertising [16]. It can be noted that many other authors also treated appropriate advertising as a traditional instrument of sales promotion and argued that the intensity of new product advertising is a factor which influences the speed of market penetration.

A good image of the company is also an important success aspect, especially for a market newcomer, so trying to create and start providing new services is prerequisite in this case. A favorable image is formed only by providing high-quality services that meet the users' requirements, representing a selected segment of the market. Services provided with appropriate advertising are an integral part of a positive image and business success.

\section{DEVELOPING THE MODEL OF ACTIONS TO PENETRATE INTO THE MATURE MAINTENANCE MARKET}

The analysis of the above-presented special and scientific literature of market penetration by business pioneers crystallized the required procedures, their content and need, as well as logical justification of their sequence. Results obtained from such analysis will help a new maintenance company to identify the ways for penetrating even into a complete market and help prepare the best business strategy which is in line with current conditions and competitive situation.

The model of actions for new entrants' market penetration, which is applicable in the maintenance sector, is given in Fig. 1. Each of the necessary actions is based on the above-mentioned research results, and the sequence of actions is substantiated by logic in accordance with service properties. Each of the necessary actions is expressed in the model components.

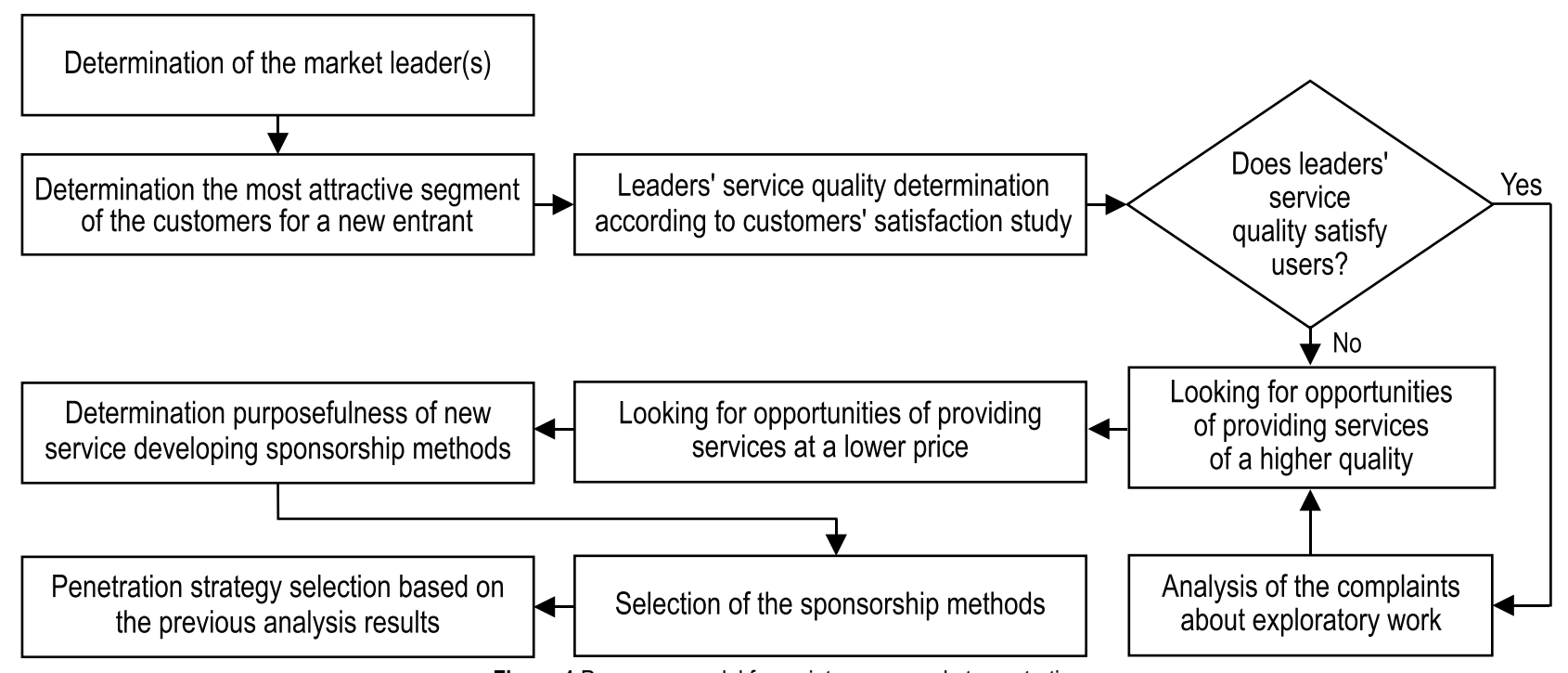

Figure 1 Processes model for maintenance market penetration

The proposed model has a flexible construction, as it provides steps for different potential solutions that are dependent on the business situation and external conditions. It is appropriate to accept the findings of Sujin Choi [17] who stated that the proper use of the market analysis results and the execution of well-planned and coordinated actions also allow newcomers to penetrate a mature market, and even a rather saturated market, and successfully develop their service business.

The following sections contain practical applications of the proposed model in real business conditions.

\section{EMPIRICAL ANALYSIS OF THE TECHNOLOGICAL EQUIPMENT MAINTENANCE SERVICES IN THE CATERING BUSINESS COMPANIES}

The following is a market research of technological equipment maintenance services in the catering services market. Conducted in Lithuania, the research and resultbased actions to penetrate the maintenance service market are characteristic not only for Lithuania. They can help penetrate the maintenance service market of any country with a market economy and legitimized competition. 


\subsection{Determination of the Market Leader(s)}

As mentioned above, investigation should start from the identification of potential competitors, their market share and market leaders. Results of the investigation and activities of the market leaders are likely to influence the order of further research. According to information of Vilnius Municipality, in the middle of 2017, there were 835 catering enterprises registered and active in the city (capital of Lithuania). If reliability of the study is $95 \%$, and the deviation is $5 \%$, it means the study should cover 264 catering companies (preferably, 50\% in open and closed networks each). A closed network means catering companies functioning within offices, other business enterprises, educational institutions, health care institutions which serve only the participants of the mentioned activities.

Open-network catering companies include restaurants, cafes, bars and other companies providing various food preparation and sales services.

It was found that significant market leaders existed neither in equipment sales nor in the field of equipment repairs. It was also found that three companies have a market share of $25 \%$ (and they were recognized as market leaders because all other firms occupied a market share of about $3-4 \%$ only).

Those results were confirmed by the analyses of sales volumes available from the Lithuanian Department of Statistics. The investigation further showed that those companies were sellers of technological equipment, not specifically engaged in equipment repairs. Equipment maintenance and warranty services were provided only as additional services (obligatory for any sellers). At the end of 2017, there were 159 companies in Lithuania selling vending equipment, of which 56 companies specializing exclusively in supplies of hardware technology and its maintenance. 112 companies provided maintenance and repair services only with regard to the equipment they were selling. Accordingly, focusing on some quality aspects of their services and identifying the degree of customer satisfaction would be a reasonable next step of the study in search for opportunities to penetrate the market, attract potential users of the services of the market leaders and other companies by offering better quality services and a wider range of services.

In order to get a more accurate picture of the situation in the existing market, interviews were also conducted with maintenance companies. The study showed that coordinated market penetration actions were carried out only by a few of the interviewed equipment maintenance and repair companies and the majority of them noted that they would expand their activities, if they knew what steps to take to penetrate the market and in what sequence.

The content of other components of the proposed model is discussed below.

\subsection{Determination of the Most Attractive User Segment for a Market Novice}

The purpose of this analysis is to determine the level of satisfaction of different segments of service users in order to identify the best possible directions for business development to be followed by a new market entrant in search for opportunities to perform better than the existing market participants and to meet any exceptional needs of the consumers. Managersor other responsible staff members of closed-network catering companies (training, medical institutions, industrial enterprises) and opennetwork catering companies were directly interviewed. The questions were exclusively related to the field of equipment repairs and maintenance. It was observed that the quality of services more frequently did not meet the requirements in closed-network companies. Even $26 \%$ of the respondents answering the question about the quality of hardware warranty service time said that the sellers of the equipment failed to comply with personnel (technicians) arrival terms, $9 \%$ said that hardware warranty repair was even poor quality, as the equipment failed quickly after being repaired. Satisfaction with the quality of warranty services in leading open-network catering companies was a little bit better. The question of whether in case of equipment failure they had to seek help from other organizations was answered in the affirmative by $33 \%$ of respondents. The above studies lead to the conclusion that the existing participants of the catering equipment servicing market are more interested in serving opennetwork companies and improving services to companies in this market segment; closed-network catering companies facing emergency equipment failure have a possibility to apply to a technical department for aid and often get it.

Equipment sellers were similarly interviewed about the quality of maintenance. The managers of these companies emphasized the excellent quality of their work. However, they did not refuse a possibility to transfer strictly technical support functions to some other economic entity, which would be able to carry out these works with excellence. Thus, the opinions of users and providers of maintenance services about the service quality appeared to be partially contradictory. Basing on the results of this study, the following generalizations can be made:

1) It is appropriate for new entrants to offer performance of warranty service, i.e. to operate on behalf of equipment sellers, to fulfill obligations to the users of maintenance services on a better and higher quality level than the sellers, to ensure certain fixed terms of arrival in the catering company and fixed repair work completion time which must be strictly followed, and to offer better prices, payment conditions and procedure. Such an approach would also facilitate the work and should be of interest to equipment sellers as they would not have to take care of the additional service, i.e. equipment repair and maintenance, and would be able to focus more on increasing the sales of technological equipment (i.e. focusing on the main activity).

2) The analysis of the quality of services provided by the existing market participants obviously points to the lack of reliability that technicians will arrive on time. This element should be improved in maintenance services. Furthermore, it is reasonable to offer maintenance services to closed-network catering companies. 


\subsection{Analysis of the Options for Improving the Quality of Catering Equipment Repair Services}

Quality improvement is one of the most important directions for penetrating into mature markets. Results of this analysis should show the aspects of the quality of services which the existing customers are not fully satisfied with. This can help find a niche in the market for new entrants whose better quality of service would attract customers' interest. Users of technological equipment maintenance services were asked about quality indicators for maintenance services that could encourage them to change service provider. The results of the analysis are presented in the Tab. 1.

Table 1 Quality indicators that may encourage customers of maintenance services to change service provider

\begin{tabular}{|l|c|c|c|c|c|}
\hline \multicolumn{1}{|c|}{ Assessments } & $\begin{array}{c}\text { Would absolutely } \\
\text { discourage (\%) }\end{array}$ & $\begin{array}{c}\text { Would } \\
\text { discourage } \\
\text { (\%) }\end{array}$ & $\begin{array}{c}\text { Would neither } \\
\text { encourage, nor } \\
\text { discourage (\%) }\end{array}$ & $\begin{array}{c}\text { Would } \\
\text { encourage } \\
\text { (\%) }\end{array}$ & $\begin{array}{c}\text { Would } \\
\text { absolutely } \\
\text { encourage (\%) }\end{array}$ \\
\hline Shortening equipment repair time & 11.1 & 11 & 28.5 & 24.8 & 24.6 \\
\hline $\begin{array}{l}\text { Improving timeliness (shortening time) of } \\
\text { technician's (mechanic's) arrival }\end{array}$ & 12.2 & 11.1 & 28.6 & 30.5 & 17.6 \\
\hline $\begin{array}{l}\text { Service price reduction, while maintaining the } \\
\text { appropriate level of quality }\end{array}$ & 11.1 & 23.3 & 20.9 & 24.5 & 20.2 \\
\hline $\begin{array}{l}\text { Improvement of technicians (mechanics) working } \\
\text { culture }\end{array}$ & 16.1 & 16 & 39.6 & 16.3 & 12.0 \\
\hline Personnel competence development & 12.2 & 13.3 & 32.3 & 22.6 & 19.6 \\
\hline $\begin{array}{l}\text { Increasing flexibility of servicing staff's working } \\
\text { hours. }\end{array}$ & 12.2 & 14.3 & 27.5 & 23.0 & 23.0 \\
\hline $\begin{array}{l}\text { Increasing clarity of information about the } \\
\text { substance of services }\end{array}$ & 11.1 & 39.8 & 40.2 & 2.6 & 6.3 \\
\hline Increasing accessibility to advertising & 55.1 & 30.8 & 10.9 & 2.1 & 1.1 \\
\hline $\begin{array}{l}\text { Increasing availability of information about } \\
\text { services }\end{array}$ & 16.1 & 29.9 & 42.9 & 5.7 & 5 \\
\hline
\end{tabular}

According to the results of interviews with catering companies' managers, it can be concluded that the quality of existing services basically satisfies the customer needs, because most of the companies are interested in better services at lower prices. However, it should be noted that faster arrival of technicians (mechanics) would nonetheless encourage $48.1 \%$ of catering companies to change the service provider. Having found the opportunities to provide services faster (earlier) than it is the case under existing contracts, a new market entrant can expect a positive decision with regard to changing the service provider whose service quality is unsatisfactory.

This, by the way, is linked to increasing the flexibility of working time, so new entrants must look for opportunities to improve activity in this area, too. Results analysis has showed that reducing time of the equipment repair is also a niche that allows market penetration, as almost half $(49.4 \%)$ of the surveyed companies are not satisfied with the quality of services in terms of time. The value of this indicator correlates with the satisfaction with staff qualifications. As new entrant's services should be provided in a shorter time, time reductions can be achieved by hiring more highly skilled employees or by adjusting the organizational aspects of this activity. It should be mentioned that during interviews with the catering companies' managers it was noticed that technical servicing companies do not comply with maintenance instructions, and repair equipment at their own discretion. Such dissatisfaction expressed by managers in some cases may also be a niche for newcomer to start a new business, ensuring that the new firm complies with the instructions extremely rigorously. One way or another, the technical maintenance instructions prepared by the manufacturers of the equipment must be strictly followed. Compliance with these instructions is a guarantee of service quality in this case.

In addition, it should be also noted that increasing the clarity of information provided about the substance of the services and increasing the availability of service information are not essential conditions for market penetration. Therefore, it can be concluded that the influence of support measures on choosing a new provider will not be high, as the existing market equilibrium basically satisfies the existing needs of the users of these services. Therefore, a better market penetration strategy is to use only some of the appropriate forms of service quality improvement.

\subsection{Analysis of the Need for Catering Equipment Repair Companies to Provide Services at a Lower Price}

The results of the investigation have showed that price reductions would be a serious ground for mature market penetration, because even $44.7 \%$ of respondents answered that they would change the existing service provider to the one offering equipment repair services of an adequate quality at a lower price. The question was intentionally worded in this strict manner so that ambiguity of answers would not distort the results [19]. In addition, respondents could better understand such a formulation of the question. It should be noted that even $60.8 \%$ of those who would like to change service providers are open-network companies; most of them are new companies which have just started their catering business. This fact can be explained by the assumption that equipment of closed-network catering companies in Lithuania is in most cases not their own property, but is owned by the serviced organization (for example, equipment of the kindergartens, schools and gymnasium canteens belongs to municipal departments of 
education). In this case, the serviced organization takes care of equipment repairs/maintenance and pays for the provision of maintenance services. It can be argued that the study results reaffirm theoretical truths that market penetration is possible by offering lower prices for services $[6,10,19]$. But in this case it is especially reasonable to offer lower prices to open-network companies, particularly catering business starters which are short of resources to develop a new business. Thus, it is relevant to use price differentiation which would increase the flexibility of activity and the ability to penetrate into the current market of maintenance services. Service price reduction could be implemented through certain, more ingenious strategies which are not typical in the area of such services (two for the price of one, $2^{\text {nd }}$ or $3^{\text {rd }}$ time free of charge, part of the service free of charge, discounts for loyal customers, discounts for young people or new users, etc.). Thus, market newcomers of the activities in question (maintenance services) should certainly look for opportunities to offer services at lower prices than they are provided by existing market players, because service users are not so much interested in excellent quality (and high price) of service. The results of the study clearly indicate that the reduction of the cost of services is a door to penetrating the existing market.

\subsection{Determining the Appropriateness of New Service Development}

In the absence of opportunities to provide services cheaper than they are provided by the market leader and other market participants in a given period, it is appropriate to use another opportunity to penetrate the market, i.e. try to provide new services. Good business performance is quite often achieved when market novices come up with new services that are close by their nature to those provided by the market leaders, but with certain modifications whose appropriateness is based on market research results. Drejeris et al. [10] examined the current situation and conditions in detail and developed realistic proposals (methodology) for the existing market participants how to determine the appropriateness of new services based on the application of quantitative methods.

The above-mentioned article proposes considering two alternatives of the appropriateness of developing service business, i.e. creating and launching a new service or increasing the volume of existing services with application of service sales promotion tools. It is recommended to determine the relevance of new services following the methodology proposed by Drejeris et al. [10]. The article offers a cyclical model for the determination of the appropriateness of new services. It indicates that customers' needs should be regularly tested in order to grasp the thread showing a decrease in customers satisfaction which, in turn, is indicative of the need to introduce a new service (or to modify the service which was already provided earlier). According to Drejeris at al. [10], developing new services should not only provide a competitive advantage and intensify sales of existing services, but also create a positive image of the company not only among existing market participants, but possibly for new entrants, too.

\subsection{Selection of Sponsorship Methods and Justification of Their Need}

In this case, the goal of advertising is to make potential customers aware of a new market participant which provides new services or provides better quality of existing service. The results of the mentioned study have shown that the influence of sponsorship measures on choosing a new service provider for repairing catering equipment will not be significant, as the well-established market equilibrium basically satisfies the customers of the existing service market. Therefore, it is appropriate to develop a penetration strategy based on measures to improve the quality of services and use only some forms of sponsorship to advertise the high quality of this type of services. In other words, new entrant's sponsorship measures should be focused only on the improvement of the quality of the offered product. The most commonly applicable and appropriate technical and organizational tool for sales activation is to create and apply a system of recommendations which includes the use of tools that make satisfied customers recommend the service to other potential service users. Such advertising is manifested both in formal and informal verbal communication among service users, which is based on information about the company or its services and dissemination of good practices. It is even recommended choosing an equipment repair service provider on the basis of positive experiences of other catering companies [20, 21]. The study on the availability of advertising showed that advertising does not have a significant impact on the choice of service providers [22]. Therefore, the degree of intensity should not be too high, and the focus for better result should be only on the high quality of service.

\subsection{Development of a Penetration Strategy}

Some authors agree on the need to carefully plan any business activity, in particular in making strategic decisions [23-25]. The study showed that possession of a penetration strategy can activate companies providing maintenance services. The penetration strategy is developed according to each of the research results, whose use will allow determining the potential business niche, clearly showing the direction in which the business entity must develop in order to penetrate the mature market. Each endpoint serves to discover possibilities to penetrate the existing market and allows mapping strategic activity guidance for achieving the organization's objectives. Penetration actions are modeled in accordance with logic and knowledge of the principles of business reality. Application of the model undoubtedly confirmed the preconditions for strategy development, the need for the model, and the relevance of its absence, while positive results of the application justified possibilities for using this model to develop penetration strategies for maintenance services in different fields of activities.

According to the results of each of the investigation actions presented in the above submitted model, the developed market penetration strategy is appropriate and the penetration strategy activities allow a new entrant to successfully penetrate the existing market. The actions for penetration strategy formulation are selected in accordance 
with the specifics of maintenance services and reflect the specific nature of Lithuanian business at the current time.

Maintenance in this case may cover a much wider range of actions: computer and car repair, maintenance of electricity, water, gas supply lines, and other rather specific activities. Each manufacturing company creates a number of jobs for providers of maintenance services. The actions of market penetration are suitable for any maintenance strategy development, since service users are interested in the same things (price, quality, accessibility, etc.). The proposed methodology can be used for creating market penetration strategies not only by business organizations, but for individuals as well.

\section{CONCLUSIONS}

The information analysis of scientific and special literature on market penetration showed that there is a lack of knowledge about penetration actions, the proposed models and methods have no examples of their practical application, and there are no data on the penetration of the processes addressed, especially with regard to the mature maintenance market. A flexible-structure model is developed consisting of 9 components: determination of market leader(s), customers' satisfaction study according to the quality of leaders' service, analysis of complaints about exploratory work, looking for opportunities of providing services of a higher quality, looking for opportunities of providing services at a lower price, determination of the purposefulness of developing new services, selection of sponsorship methods, and selection of a penetration strategy based on the analysis results.

According to the actions of the proposed model components, empirical research was conducted under real business conditions. The results revealed the existence of certain instruments for realistic penetration into the mature market for maintenance business under specific conditions and circumstances allowing new entrants to successfully penetrate into the existing market. The results of the use of the model showed that the proposed actions are clearly sufficient to develop a successful market penetration strategy and affirmed the sequence of the actions and appropriateness of their content.

The use of the proposed model will allow companies and individuals providing maintenance services to plan and structurally justify their market penetration actions, reduce possible risks of market penetration failure and provide the opportunity to achieve better economic results for maintenance business. Limitation of suggested model is manifested in possibilities of use, because it is suitable for maintenance purposes only. Research of other types of services penetration into some market is a further area of our research.

\section{REFERENCES}

[1] Yitshaki, R. \& Kropp, F. (2016). Entrepreneurial passions and identities in different contexts: a comparison between high-tech and social entrepreneurs. Entrepreneurship \& Regional Development. An International Journal, 28, 206233.

[2] Freeman, R. E. (2010). Strategic management: a stakeholder approach. Cambridge University Press, New York. https://doi.org/10.1017/CBO9781139192675
[3] Cho, S., Mathiassen, L., \& Gallivan, M. (2009). Crossing the diffusion chasm: from invention to penetration of a telehealth innovation. Information Technology \& People, 22, 351-366. https://doi.org/10.1108/09593840911002450

[4] Meyer, K. E., \& Yen Thi Thu Tran (2006). Market Penetration and Acquisition Strategies for Emerging Economies. Long Range Planning, 39, 177-197. https://doi.org/10.1016/j.lrp.2006.04.004

[5] DiRenzo, M. S., Weingarden, S. M., \& Resick, C. J. (2016). Following the Leader in Sports: A Targeted Review and a Rally for Extended Research, in Claudia Peus, Susanne Braun, Birgit Schyns (ed.) Leadership Lessons from Compelling Contexts (Monograph in Leadership and Management), 8, 67-93. Emerald Group Publishing Limited, Bingley. https://doi.org/10.1108/S1479-357120160000008003

[6] Kotler, P. \& Armstrong, G. (2012). Principles of Marketing ( $14^{\text {th }}$ Edition). Prentice Hall, New Jersey.

[7] Rungie, C., M., Uncles, M., \& Laurent, G. (2013). Integrating consumer characteristics into the stochastic modelling of purchase loyalty. European Journal of Marketing, 47, 1667-1690. https://doi.org/10.1108/EJM-12-2010-0656

[8] Tax, S. S. \& Brown, S. W. (1998). Recovering and Learning from Service Failure. MIT Sloan Management Review, 40, 1, 2-10.

[9] Bohli, J. M., Sorge, Ch., \& Wesgoff, D. (2009). Initial observations on economics, pricing, and penetration of the internet of things market. ACM SIGCOMM Computer Communication Review, 39, 50-55. https://doi.org/10.1145/1517480.1517491

[10] Drejeris, R., Bivainis, J., Tunčikienè, Ž., \& Drejerienè, E. (2013). Determining the purposefulness of new services on the grounds of the results of quantitative analysis. Journal of business economics and management, 14, 791-805. https://doi.org/10.3846/16111699.2013.772917

[11] Nikolaidis, Y. \& Bakouros, Y. (2009). Innovation penetration into a region with specific features: the case of Crete, Greece. International Journal of Entrepreneurship and Innovation Management, 9, 118-138. https://doi.org/10.1504/IJEIM.2009.023848

[12] Vlachos, P., Giaglis, G., Lee, I., \& Vrechopoulos, A. (2011). Perceived electronic service quality: some preliminary results from a cross-national study in mobile internet services. International Journal of Human-Computer Interaction, 27, 217-244. https://doi.org/10.1080/10447318.2011.537207

[13] Liu, R. R. \& McClure, P. (2001). Recognizing cross-cultural differences in consumer complaint behavior and intentions: an empirical examination. Journal of Consumer Marketing, 18, 54-75. https://doi.org/10.1108/07363760110365813

[14] Sood, A. G., James, M., \& Tellis, G. J. (2009).Functional regression: a new model for predicting market penetration of new products. Marketing Science, 28(1), 36-51. https://doi.org/10.1287/mksc.1080.0382

[15] Oke, S. A. (2007). Six Sigma: a literature review. South African Journal of Industrial Engineering, 18, 109-129.

[16] Swami, S. \& Dutta, A. (2010). Advertising strategies for new product diffusion in emerging markets: Propositions and analysis. European Journal of Operational Research, 204, 648-661. https://doi.org/10.1016/j.ejor.2009.11.009

[17] Sujin Choi. (2011). Facilities to service based competition, not service to facilities based, for broadband penetration: a comparative study between the United States and South Korea. Telecommunications Policy, 35, 804-817. https://doi.org/10.1016/j.telpol.2011.08.003

[18] Jose, A. \& Goldfried, M. (2008). Transtheoretical Approach to Case Formulation. Cognitive and Behavioral Practice, 15, 212-222. https://doi.org/10.1016/j.cbpra.2007.02.009

[19] Indounas, K. \& Avlonitis, G. (2011). New industrial service pricing strategies and their antecedents: empirical evidence 
from two industrial sectors. Journal of Business \& Industrial Marketing, 26, 26-33. https://doi.org/10.1108/08858621111097184

[20] Munford, R. \& Sanders, J. (2016). Understanding service engagement: young people's experience of service use. Journal of Social Work, 16, 283-302. https://doi.org/10.1177/1468017315569676

[21] Dong-Hee Shin, Seungjo Lee, \& Yujong Hwang. (2017). How do credibility and utility play in the user experience of health informatics services? Computers in Human Behavior, 67, 292-302. https://doi.org/10.1016/j.chb.2016.11.007

[22] Doshi, P. \& Pandya, V. (2015). A revier on design and development of decision support system for right understanding about some food product supported by advertisement in India. International Journal of Advanced Research in Engineering and Applied Sciences, 4, 44-52.

[23] Blackburn, R. A., Hart, M., \& Wainwright, T. (2013). Small business performance: business, strategy and ownermanager characteristics. Journal of Small Business and Enterprise Development, 20, 8-27. https://doi.org/10.1108/14626001311298394

[24] Ates, A., Garengo, P., Cocca, P., \& Bititci, U. (2013). The development of SME managerial practice for effective performance management. Journal of Small Business and Enterprise Development, 20, 28-54. https://doi.org/10.1108/14626001311298402

[25] Meyer, K. E. \& Peng, M. W. (2016). Theoretical foundations of emerging economy business research. Journal of International Business Studies, 47, 3-22. https://doi.org/10.1057/jibs.2015.34

\section{Contact information:}

Rolandas DREJERIS, Assoc. Professor, Doctor of Social Sciences

(Corresponding author)

Vilnius Gediminas Technical University,

Saulètekio av., 11, Vilnius, LT-10223, Lithuania

Aleksandras Stulginskis University

Studentu 11, Akademija, LT-53361, Kauno raj. Lithuania

E-mail: rdrejeris@gmail.com

Eglè DREJERIENĖ, Assoc. Professor, Doctor of Biomedical Sciences

Lithuanian University of Health Sciences,

A. Mickevičiaus str. 9, LT-44307 Kaunas, Lithuania

E-mail: edrejeriene@gmail.com 